\title{
Zur Kenntniss der Borsäure und über eine direkte gewichtsanalytische Bestimmung derselben.
}

Von Professor Dr. Partheil in Bonn.

Einleitend bestütigt Vortragender im Gegensatz zu den von Beermann (Dissertation, Erlangen 1898, 17) gemachten Angaben, dass die beiden bekannten titrimetrischen Methoden zur Bestimmung der Borsäure wohl ausführbar sind und bei Anwendung der nöthigen Vorsichtsmassregeln befriedigende Ergebnisse liefern. Die weiteren gemeinsam mit Ros e angestellten Versuche befassten sich in erster Linie mit der Flüchtigkeit und Löslichkeit der Borsäure und ergaben folgendes: In verschiedenen Lehrbüchern wird Metaborsäure $\left(\mathrm{HBO}_{2}\right)$ als langsam aber vollkommen flüchtig bezeichnet. Diesen Angaben liegen Versuche von Sehaffgotsch zu Grunde, die insofern zu irrthümlichen Schlüssen Veranlassung gegeben haben, als es sich um eine Verflüchtigung der Säure durch die als Wärmequelle dienenden. Wasserdämpfe handelte. Beim 12-tägigem Erhitzen der Borsäure im Weintrockenschrank $\left(105^{0}\right)$ verflüchtigten sich nur sehr kleine Mengen derselben mit dem entweichenden Molekül Wasser. Im Vakuumexsiccator über Schwefelsäure kann Borsäure $\left(\mathrm{H}_{3} \mathrm{BO}_{3}\right)$ ohne Gewichtsverlust aufbewahrt werden. Wird Borsäure mit Aether übergossen und dieser dann abdestillirt, so gehen kleine Mengen Borsäure, wenn auch nicht in dem Maasse wie bei Wasser und Alkohol, mit den Aetherdämpfen fort. Dieser Verlust lässt sich vermeiden beim Absaugen des Aethers im Vakuum über Schwefelsäure. Von der Borsäure lösen sich in 100 Thln. wssserfreiem Aether 0,0077 Thle. und in wasserbaltigem Aether 0,188 Thle. Beim Schütteln von gleichen Raumtheilen Aether und 1/10 N.-Borsäurelösung tritt das Theilungsverhältniss 1:34,2 ein. Diese Vorversuche zeigten den Weg zu einer direkten gewichtsanalytischen Bestimmung der Borsäure. Zur Ausführung derselben wird eine salzsäurehaltige Borsäurelösung in einem besonderen von Partheil und Rose konstruirten Apparate (Lieferant C. Gerhardt in Bonn. Preis 12,00 M.) mit grösseren Mengen Aether durch Perforation extrahirt, im tarirten Kölbchen nach Absaugen des Aethers im Vakuumexsiccator über Schwefelsäure getrocknet und schliesslich als $\mathrm{H}_{3} \mathrm{BO}_{3}$ gewogen. Bei einer Extraktionsdauer von 18 Stunden erhielt Vortragender sehr gerıaue Ergebnisse. Praktische Anwendung fand dieses Verfahren bei der Bestimmung der Boreäure in Mineralien. Dabei ist die Anwendung von Schwefelsäure und Salpetersäure als Lösungsmittel zu vermeiden, weil diese beim Extrahiren mit in den Aether übergehen. Störend wirkt ferner Phosphorsäure und Eisen, die in der zu extrahirenden Flüssigkeit zuvor als Ferriphosphat bezw. Berlinerblau entfernt werden müssen. Sollten bei der Extraktion andere nicht flüchtige Substanzen mitübergegangen sein, so bleiben dieselben nach Verjagen der Borsäure mit Methylalkohol zurück und können nach Wägung in Abzug gebracht werden. Eingehendere Mittheilungen über den quantitativen Nachweis der Borsäure besonders in Nahrungsmitteln stellt Vortragender demnächst in Aussicht.

P. Buttenberg.

\section{Ueber die quantitative Bestimmung der Milchsäure.}

Von Professor Dr. Partheil in Bonn.

Der vom Vortragenden für die Bestimmung der Borsäure konstruirte Perforator konnte mit gutem Erfolg auch zur gewichtsanalytischen Bestimmung der Milchsäure verwendet werden. Diesbezügliche von Gronover ausgeführte Versuche gaben bei 
0,5-0,6 g Milchsäure nur Differenzen von $0,002-0,003 \mathrm{~g}$. Es ist dies insofern bemerkenswerth, als es Kunz (Diese Zeitschr. 1901, 4, 673) nicht gelang, durch Extraktion mit Aether im Schacherl'schen Apparat Milchsäure genügend genau quantitativ zu bestimmen.

Partheil hält für den vorliegenden Zweck seinen Apparat für vortheilhafter, weil hier das Verhältniss des als Extraktionsmittel dienenden Aethers zu der zu extrahirenden Flüssigkeit ein günstigeres ist.

P. Buttenberg.

\section{Ernährung, Nahrungsmittel, Nährpräparate.}

Von Dr. Heinrich Zellner in Hannover.

Die Kenntniss der rein chemischen Natur eines Nährmittels genügt noch nicht, un sich ein Urtheil über dessen Nährwerth zu bilden. Dazu ist eine gewisse Vertrautheit mit den Grundanschauungen der Diätetik und Ernährungstherapie nothwendig. Die praktischen Apotheker zum Studium auf diesem Gebiete zu verunlassen, soll der Zweck des Vortrages sein.

Nach eingehender Ausführung über den Begriff der Ernährung bespricht Vortragender den Zweck der einzelnen in unseren Nahrungsmitteln entbaltenen Nährstoffe und zeigt, welche Rolle die Genussmittel spielen.

Der Werth oder Unwerth eines Nahrungs- oder Nährmittels lässt sich durch künstliche Verdauung, geeigneter durch physiologische Versuche an Menschen feststellen, doch der beste Aufschluss über eine wirkliche Bedeutung kann nur dureh jahrelang fortgesetzten Verbrauch bei zahlreichen, im Leben stehenden Menschen erbracht werden.

Die Erkenntniss der Wichtigkeit einer rationellen Ernährung hat das Emporblühen der Nahrungsmittelindustrie zur Folge gehabt. Durch Erschliessung bisher weniger verwerthbarer Quellen sind eine Reihe von Präparaten geschaffen, die gestatten, die Nährstoffe in koncentrirter bezw. leicht verdaulicher Form dem Körper darzubieten. Für die Krankenkost mögen diese Präparate von Wichtigkeit sein; eine bessere und finanziell vortheilhaftere Ernährung von gesunden Menschen hat sich bis jetzt durch die Erschliessung neuer Eiweissquellen nicht ermöglichen lassen. Vergleicht man z. B. unter Zugrundelegung des Eiweissgehaltes den Nährwerth von Tropon mit dem von Schellfisch, Fleisch, Küse, Brot und Hülsenfrüchten, so ergiebt sich, dass das Eiweiss dieser natürlichen Nahrungsmittel nicbt theurer sondern bei Schellfisch und Leguminosen sogar wesentlich billiger ist. Die Ausnutzbarkeit des Eiweisses im Tropon ist zwar grösser als wie bei Vegetabilien, dafür führt man jedoch durch die letzteren dem Körper gleichzeitig andere werthvolle Stoffe zu.

Vortragender hat durch Umfrage in den deutschen Apotheken Erhebungen über den Verbrauch der einzelnen Nährpräparate angestellt, bei denen sich ergeben hat, dass Somatose am meisten abgesetzt wird, in zweiter Linie die zwar weniger als Nährmittel in Frage kommenden Fleischextrakte, Fleischsäfte und Blutpräparate, denen sich Tropon, Plasmon, Sanatogen, Nährstoff Heyden, Nutrose anschliessen. Die übrigen Nährmittel werden bedeutend weniger verbraucht. Floischextrakt ist bei den zur Verabreichung kommenden geringen Mengen kein direktes Nährmittel wohl aber durch seinen Gehalt an Extraktisstoffen und Salzen ein sehr werthvolles Genussmittel. Maggi's Suppenwürze, ein Extrakt aus Pflanzenstoffen, 